\title{
Thermo-economic Analysis of Gas Engine Combined Heating and Power System
}

\author{
Muharrem Imal (Corresponding author) \\ Kahramanmaras Sutcu Imam University, Department of Mechanical Engineering, \\ Kahramanmaras, Turkey \\ E-mail: muharremimal@ksu.edu.tr: \\ Ayse Kubra Paksoy \\ Kahramanmaras Sutcu Imam University, Department of Mechanical Engineering, \\ Kahramanmaras, Turkey \\ E-mail: aysekubrapaksoy@gmail.com
}

\begin{abstract}
Industrial combined heat-power systems are to obtain electric and steam from the same gas engine using a single type of fuel. In the combined heating and power systems, the cooling cycle is also used. In this study, low cost and high profitability heating and power system were established in an industrial process and economically evaluated. The energy expenses of the plant were calculated; the cogeneration system is designed and has been activated. The electricity, heating energy amounts obtained by the cogeneration system were determined. The economic analysis of the system's input values and the economic analysis of the output values were made comparatively and the first investment payback period has been calculated. Both systems have been found to be profitable for the process but the repayment period was different. The efficiency of the first system was $90.78 \%$ and the payback period was 3,007 years, the efficiency of the second system was $90.74 \%$ and the payback period was 2,671 years.
\end{abstract}

Keywords: Gas Engine, Combined Heating and Power, Economic Analysis

DOI: $10.7176 / \mathrm{JSTR} / 7-10-04$

\section{Gaz Motorlu Birleşik Isı-Güç Üretim Sisteminin Termoekonomik Analizi}

Özet

Endüstriyel gaz motorlu birleşik ısı-güç sistemleri, yakıtın kimyasal enerjisini kullanarak aynı sistemde elektrik ve ısı enerjisinin üretilmesidir. Gaz motorlu birleşik ısıtma ve güç sistemlerinde, soğutma çevrimi de kullanılır. Bu çalışmada, maliyeti düşük, karlılığı yüksek birleşik ısı-güç sisteminin bir endüstriyel tesise uygulanması ve ekonomik açıdan değerlendirilmesi yapılmıştır. Tesisin enerji giderleri ölçülerek sistem dizaynı yapılmış maliyeti uygun olan sistem işletmeye alınmıştır. Gaz motorlu birleşik 1sı-güç sistemi ile elde edilen elektrik, 1S1 enerjisi miktarları tespit edilmiştir. Sistemin yakıt girdi değerleri ile enerji çıktı değerlerinin ekonomik analizi karşılaştırmalı bir şekilde yapılarak, ilk yatırımının geri ödeme süresi bulunmuştur. Her iki sisteminde endüstriyel tesis için kârlı olduğu hesaplanmış ancak geri ödeme süresinin farklı olduğu görülmüştür. Birinci sistemin verimi \%90,78 ve geri ödeme süresi 3,007 y1l, ikinci sistemin verimi \%90,74 ve geri ödeme süresi 2,671 yıl bulunmuştur.

Anahtar Kelimeler: Gaz Motoru, Birleşik Isı Güç Sistemi, Ekonomik Anali

\section{Giriş}

Dünya ülkelerinin endüstriyel gelişmesi sonucu, artan enerji ihtiyacı büyük yatırımlar gerektiren bir sorun olmaktadır. Türkiye'de elektrik üretimi için kurulu gücü Mart 2021 dönemi itibariyle 97.069,7 MW ‘a ulaşmıştır. Elektrik enerjisi üretiminde enerji kaynaklarının payına bakıldığında \%41 ile doğal gazdan üretim yapıldığı görülmektedir. Doğal gazdan sonra elektrik üretiminin \% 17 si hidroelektrik barajlarından, \%16 s1 ithal kömür santrallerinden ve \%12 si linyit

25 | P a g e

www.iiste.org 
kullanan termik santrallerden gerçekleşmiştir [1].

Endüstriyel birleşik ısı ve güç sistemlerinde doğalgaz kullananılarak yakıtın daha verimli şekilde yanmasını sağlamak, ısıl veriminin artmasını ve birim yakıt maliyetlerinin azalmasını sağlayacaktır. $\mathrm{Bu}$ nedenle, sınırlı enerji kaynaklarının verimli kullanımında en dikkat çekici yöntemlerden biri atık 1sı geri kazanımıdır [2]. Geleneksel bir ısı prosesinde üretilen enerjinin yaklaşık olarak \%16-20 kadarı baca veya egzoz gazlarıyla sistemden çevreye atılır. Bu oranın çok yüksek olması yüzünden, ısı geri kazanım sistemlerinin kullanılması enerji ekonomisi açısından gerekli olmaktadır [3]. Gaz motorlu birleşik $1 s 1$ güç sistemleri, tek bir yakıtın 1sı girdisi ile birden fazla enerji çıktısı sağlanabilmektedir. $\mathrm{Bu}$ sistemlerde doğalgaz kullanımı hem enerji değeri

olarak hem de isıl verim olarak daha performanslı olmaktadır. Kurulacak sistemde doğalgaz yakıtı girdi olarak kullanılarak, elektrik ve buhar üretilmektedir. Gaz motorlu birleşik 1s1 güç sistemleri ile geleneksel sistemlerden farklı olarak atık $1 \mathrm{~s} 1$ enerjisinin de kullanımı sonucunda 1 sil verim artirılmaktadır [4].

Planlaması iyi yapılmış bir birleşik ısı güç sistemi, düşük maliyetle, verimli enerji ve ısı üretimi imkânı verir. [5]. Yanlış sistem seçimi maliyeti artııır ve işletmeyi zarar ettirir [6]. Bu nedenle kapasite seçiminin doğru yapılması önemlidir [7]. Birleşik 1sı sistemlerinin konutlarda kullanımı amacıyla yapılan çalışma sonucunda enerjinin yerinde ve çoklu üretiminin daha verimli ve ekonomik olduğu vurgulanmıştır [8]. Birleşik isıtma ve soğutma sistemi kurulacak bir proses için sistemden elde edilen 1S1 enerjisinden mümkün olduğu kadar fazla yararlanılmalıdır. Bu sayede kayıplar azaltılarak, toplam fayda artırılacaktır [10-12]. Yapılan çalışmalarda baca gazı atık 1sısı ve motor soğutma suyu isı geri kazanımı için yoğuşmalı ısı değiştiricisi tasarlamış ve performans analizlerini yapılmıştır [13-15]. Atık Isı geri kazanımı için demir çelik sektöründe çeşitli çalışmalar yapılarak reel işletme verileri termodinamik, teknoekonomik ve emisyon kontrolü açısından değerlendirilmiştir. Çalışmalar sonucunda atık 1sı geri kazanımı ile 1sı ve ekonomik karlılığın arttığı ve eksoz emisyonlarının azaldığ görülmüştür [16-17]. Bu çalş̧mada, bir sanayi tesisinde işletmenin elektrik ve buhar ihtiyaçlarını karşılamak üzere kurulacak olan gaz motorlu birleşik 1sı güç santrali ve atık 1 sı geri kazanım sistemlerinin karşılaştırılması ile enerji üretiminin termoekonomik analizi yapılmıştır.

\section{Materyal ve Metot}

Gaz motorlu birleşik 1sı güç santrali, düşük maliyetle, verimli bir şekilde enerji ve 1sı üretilmesini sağlar. Tesis kurulumunda ilk olarak işletmenin yıllık elektrik, 1sı enerjisi ve soğutma enerjisi giderlerinin tespiti için fizibilite çalışması yapılmıştır. Fizibilite sonucunda işletmenin enerji ihtiyaçlarının karşılanabilmesi için birleşik 1sıtma ve soğutma grubunun model belirlenmesi gerçekleştirilmiştir. İkinci olarak belirlenen sistemlerin karşılaştırılması ve ekonomik analizi yapılmıştır.

\subsection{Endüstriyel İşletmenin Elektrik ve Iss Enerjisi İhtiyacı}

İşletmenin diğer enerji ihtiyaçları da göz ününde bulundurulduğunda yaklaşı $1230 \mathrm{~kg} / \mathrm{h}$ ile $1238 \mathrm{~kg} / \mathrm{h}$ arası buhar kapasitesine ihtiyaç duyulmaktadır. Toplam enerji yükünü karşılamak için doğal gaz yakıtlı gaz motoru kullanılmaktadır. Tesisin yıl boyunca aylık elektrik ihtiyacının değişimi Şekil 1.1'de verilmiştir. Buna bağlı olarak işletmenin yıl boyunca aylık buhar tüketiminin değişimi Şekil 1.2'de verilmiştir.

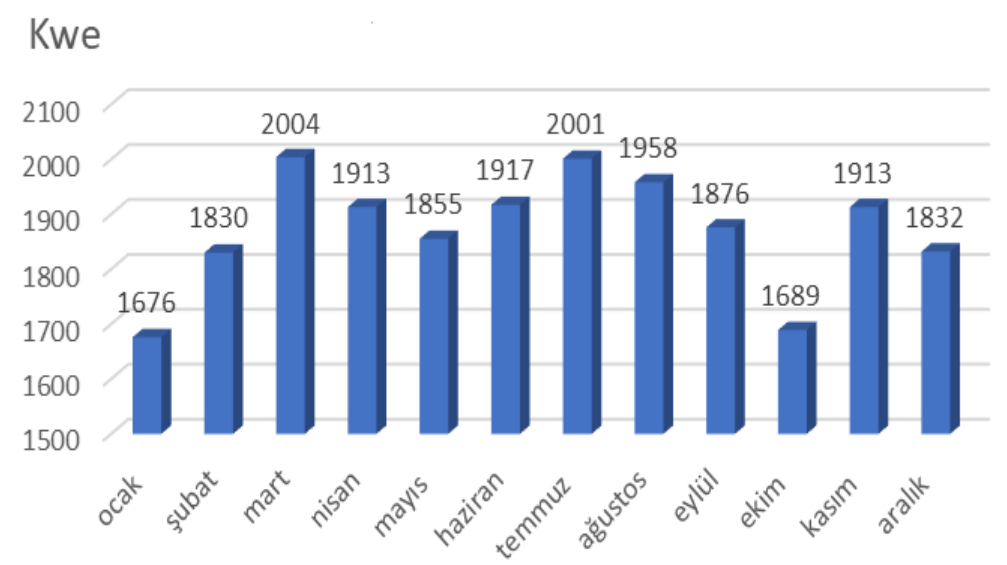

26 I P a g e

Şekil 1.1. İşletmenin yıl boyunca aylık elektrik tüketimi (kWe) 


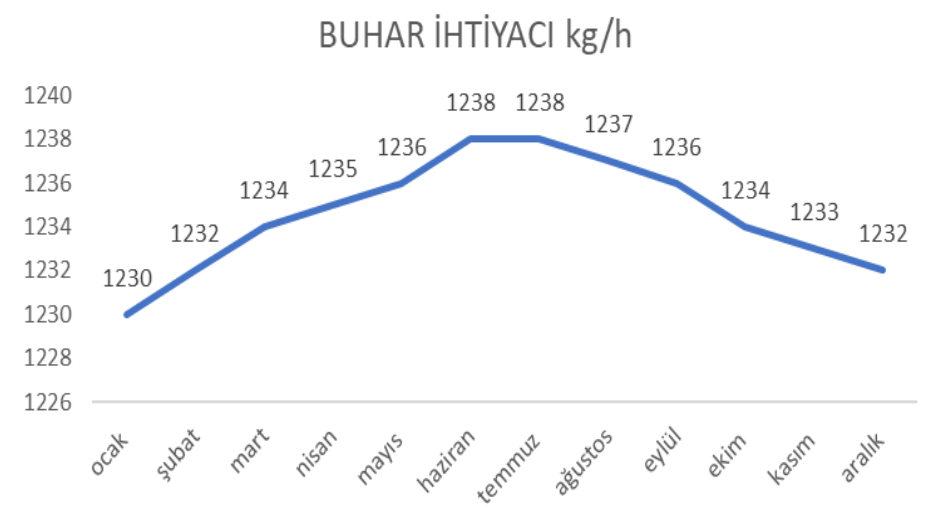

Şekil 1.2. İşletmenin yıl boyunca aylık buhar tüketimi $(\mathrm{kg} / \mathrm{h})$

\subsection{Sistem Seçimi}

Gaz motorlu birleşik ısı güç sisteminde elektrik üretimi gerçekleştirilirken açığa çıkan atık 1sı enerjisini de kullanmak amacıyla motor blok ısısının bir isı eşanjörü ile 1sı geri kazanımı yapılacaktır. Motor egzoz gazı 1sı enerjisini kullanmak için atık 1sı kazanı ile 1sı geri kazanımı yapılarak 1sıl verim en yüksek değere çıkarılacaktır. Endüstriyel işletmenin elektrik ihtiyaçları göz önünde alındığında elektrik tüketiminin en düşük olduğu ay 1676 kwe ile Ocak ayı ve elektrik tüketiminin en yüksek olduğu ay ise 2004 kwe ile Mart ayıdır. Buhar tüketimi en düşük Ocak ayında $1230 \mathrm{~kg} / \mathrm{h}$ olarak, en yüksek buhar tüketimi ise $1238 \mathrm{~kg} / \mathrm{h}$ olarak Haziran ve Temmuz aylarında gerçekleşmektedir. Sistem kurulurken elektrik üretimi öncelikli ihtiyaç olarak alınmıştır. Birleşik ısı ve güç tesisinde, sistemin kolay devreye alınabilmesi, elektriksel veriminin yüksek olması ve yakıt türü olarak doğal gaz kullanılabilmesini sağlayan gaz motoru ünitesine karar verilmiştir. Böylece hem elektrik hem de buhar gereksiniminin tek bir sistem ile karşılanması amaçlanmıştır. Ayrı ayrı sistemlerle elektrik ve buhar üretmek yerine tek bir sistem elektrik ve buhar üretimi yapılarak yatırım ve tesis maliyetleri düşürülmüsşür [18].

Yapılan çalışmalar sonucu gaz motoru modelleri üzerinde kapasite analizi yapılarak, MWM markasının üretimi olan Tcg v20 gaz motoru sistemi ile Tcg v16 gaz motoru sistemi arasında kiyaslama yapılmıştır. İşletmenin Şekil 1.1'de verilen yıl boyunca aylık elektrik tüketim verileri incelendiğinde saatlik en düşük elektrik tüketiminin Şubat ayında, saatlik maksimum elektrik tüketiminin Ağustos ayında gerçekleştiği tespit edilmiştir. İşletmenin elektrik yükünün belirlenmesinde maksimum elektrik tüketiminin gerçekleştiği Ağustos ayı baz alınarak $2670 \mathrm{kWh}$ olarak belirlenmiştir. Yapılan piyasa araştırması sonucunda, verim kayıpları da göz önünde bulundurularak elektriksel çıktısı $1605 \mathrm{kWe}$ ve $2056 \mathrm{kWe}$ olan iki adet MWM marka gaz motoru Tcg v20 ile Tcg v16 sistemleri tercih edilerek işletme ihtiyaçlarının karşılanması için kullanılmasına karar verilmiş̧ir. Tcg v20 ile Tcg v16 gaz motoru sistemlerinin teknik özellikleri çizelge $2.1^{\prime}$ de, gaz motoru sistemlerinin ssıl çevrimi şekil 2.1 'de verilmiştir.

Çizelge 2.1. Tcg v20 ile Tcg v16 gaz motoru sistemlerinin teknik özellikleri [11]

\begin{tabular}{|l|l|l|}
\hline Gaz Motoru Modeli & TCG V16 & TCG V20 \\
\hline Motor gücü & $1605 \mathrm{kw}$ & $2056 \mathrm{kw}$ \\
\hline Üretilen Elektrik gücü & $1560 \mathrm{kw}$ & $2000 \mathrm{kw}$ \\
\hline Yakıt tüketimi & $3608 \mathrm{kw}$ & $4577 \mathrm{kw}$ \\
\hline Egzos atık 1sı1s1 & $806 \mathrm{kw}$ & $972 \mathrm{kw}$ \\
\hline Ceket suyu atık 1s1s1 & $774 \mathrm{kw}$ & $1005 \mathrm{kw}$ \\
\hline Intercooler atı 1s1 gücü & $134 \mathrm{kw}$ & $178 \mathrm{kw}$ \\
\hline Sistemin elektriksel verimi & $43,24 \%$ & $43,7 \%$ \\
\hline Sistemin 1s1l verimi & $47,51 \%$ & $47,08 \%$ \\
\hline Sistemin toplam verimi & $90,74 \%$ & $90,78 \%$ \\
\hline
\end{tabular}



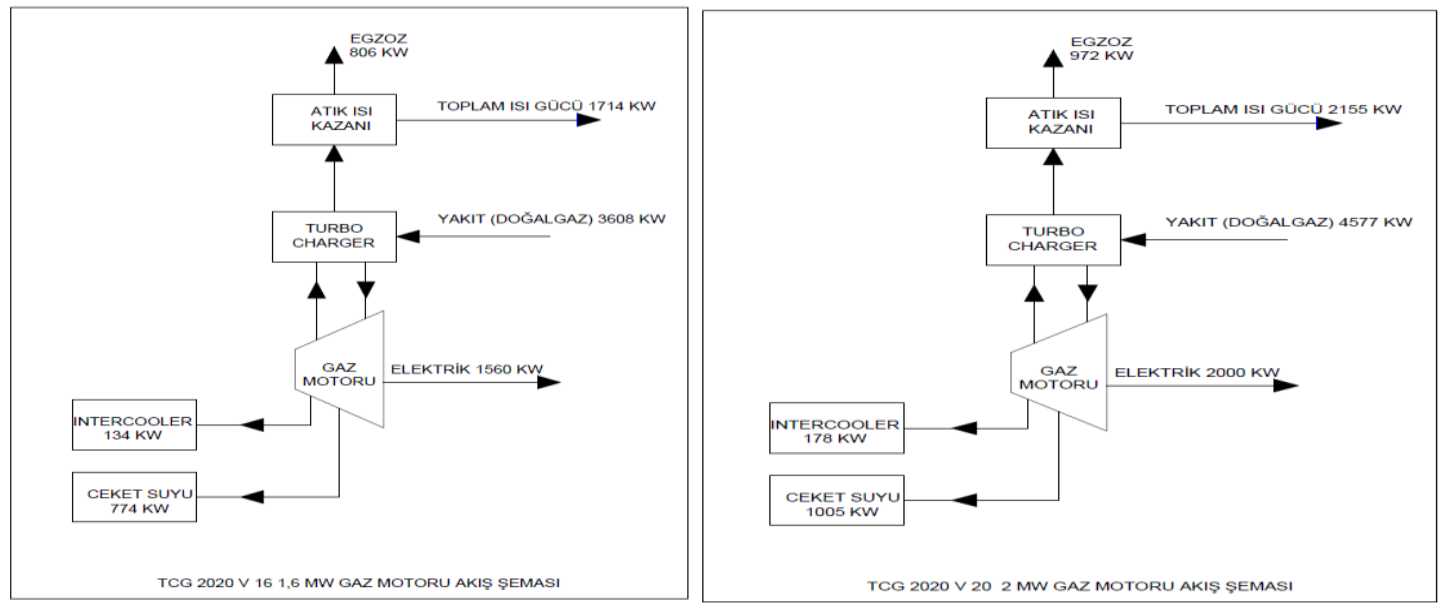

Şekil 2.1. Tcg v20 ile Tcg v16 gaz motoru sistemlerinin 1 s1l çevrimi

Tcg v20 ile Tcg v16 gaz motoru sistemlerinin termodinamik özellikleri Çizelge 2.2’ de verilmiştir.

Çizelge 2.2. Tcg v20 ile Tcg v16 gaz motoru termodinamik özellikleri

\begin{tabular}{|c|c|c|}
\hline & $\begin{array}{l}\text { TCG V16 } \\
1,6 \mathrm{MW}\end{array}$ & $\begin{array}{l}\text { TCG V20 } \\
2 \mathrm{MW}\end{array}$ \\
\hline $\begin{array}{l}\text { Sistemde kulanılacak yakıt miktarı (doğalgaz) } \\
\mathrm{m}^{3} / \mathrm{h}\end{array}$ & 398 & 497 \\
\hline Baca gazı debisi $\mathrm{m}^{3} / \mathrm{h}$ & 8787,2 & 10984 \\
\hline Baca gazı evaporatör giriş sıcaklığ $1^{\circ} \mathrm{C}$ & 419 & 419 \\
\hline Baca gazı ekonomizer çıkış sıcaklı̆̆ $1{ }^{\circ} \mathrm{C}$ & 196 & 196 \\
\hline Kazan besi suyu sıcaklı̆g $1{ }^{\circ} \mathrm{C}$ & 102 & 102 \\
\hline Besi suyu entalpi değeri kj $/ \mathrm{kg}$ & 427,541 & 427,541 \\
\hline Buhar çıkış sıcaklı̆g $1^{\circ} \mathrm{C}$ & 175 & 175 \\
\hline Buharın entalpi değeri kj/kg & 2773,1 & 2773,1 \\
\hline Buharın kütlesel debisi kg/s & 1250 & 1300 \\
\hline Buhara aktarılan 1s1 miktarı kw & 1714 & 2262 \\
\hline
\end{tabular}

Üretici firma tarafindan motorun teknik verilerine göre motor çalışma yükleri incelendiğinde motor yükünün \%50’nin altında çalıştırılması motor verimini düşürmektedir. Bu husus göz önünde bulundurularak motor yükünün \%50-100 arasında çalıştırılması sağlanarak termo-ekonomik analiz yapılmıştır [9].

\subsection{Gaz Motorlu Birleşik Isı-Güç Sistem Dizaynı}

Gaz motorlu birleşik ısı güç sisteminde elektrik enerjisi üretimini gerçekleştirecek gaz motoru-jeneratör grubu elektrik enerjisini üretirken, meydana gelen atı $1 \mathrm{~S} 1$ enerjisinden de buhar üretmek için yararlanılır. Motor blok ısısını kullanacak ısı eşanjörü ve motor egzoz gazı 1sısını kullanacak atık 1sı kazanı ile buhar ve sıcak su üretilirken bazı büyük kapasiteli sistemlerde motorun yağlama yağının atık 1sisı da kullanılır. 

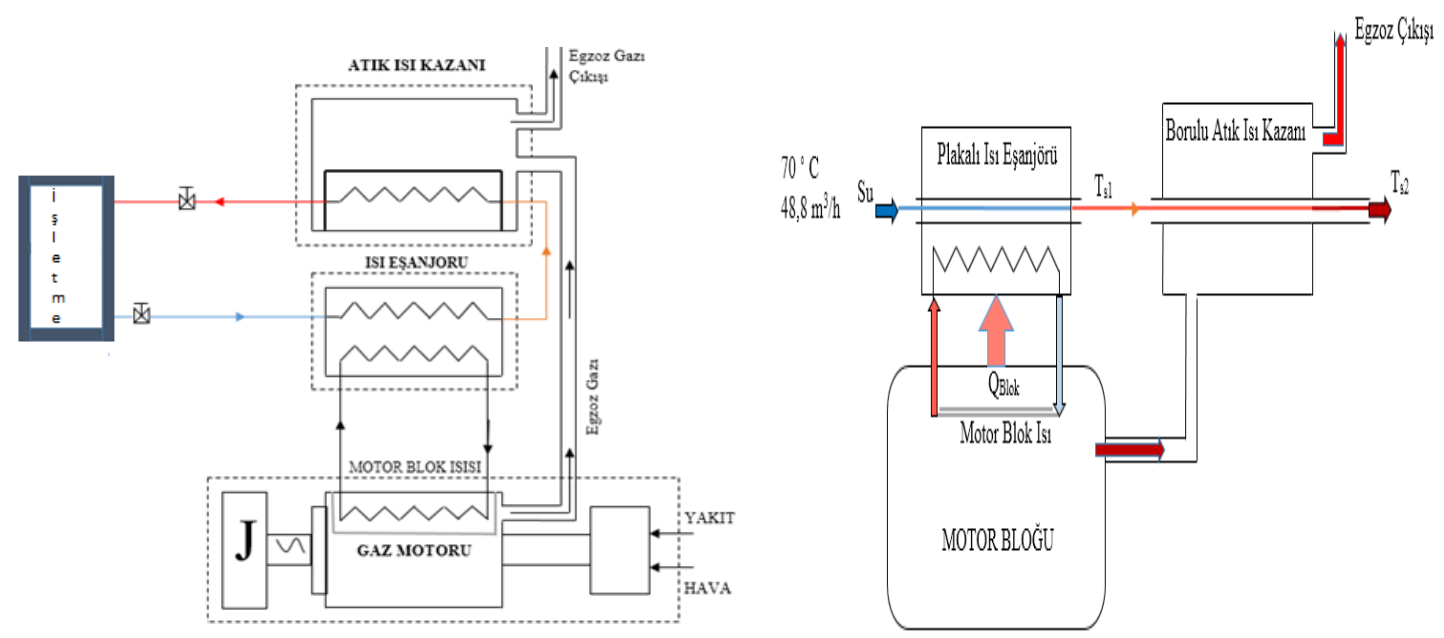

Şekil 2.2. Birleşik 1sı güç sistemi (a) ve atık 1sı (b) akış diyagramı [18]

\subsubsection{Atık Isı Kazanı}

Gaz motorlu birleşik ısı ve güç sistemlerinde meydana gelen atık ısının geri kazanımı amacıyla iki farklı alt sistem ile 1sı enerjisi üretimi gerçekleştirilir. Bu alt sistemlerden birincisi motor blok 1sısının kullanılması ile atık ısıdan yararlanmak ve ikincisi atılan egzoz gazlarının atık 1sısını kullanmaktır. Ayrıca büyük kapasiteli sistemlerde motor yağlama sistemindeki atık 1sıdan da yararlanılır. Gaz motorunun 1sı eşanjörünü ve atık ısı kazanını besleyeceği varsayılarak projelendirme yapılır. Fizibilitesi yapılan gaz motoru atık 1sı sisteminde 1 sı enerjisini taşıyacak olan akışkanın $48,8 \mathrm{~m}^{3} / \mathrm{h}$ debi ve $70{ }^{\circ} \mathrm{C}$ dönüş sıcaklığında olduğu kabul edilerek tasarım yapılmıştır. Isı taşıyıcı olarak kullanılan proses akışkanına önce 1sı eşanjörü yardımıyla motor blok 1sıs1 aktarılarak akışkan sıcaklığ1 $T_{\mathrm{s} 1}$ değerine yükselmektedir, daha sonra proses akışkanı egzoz gazlarının ısısını almak için borulu atık ısı kazanına gönderilir ve akışkan sıcaklığ1 $\mathrm{T}_{\mathrm{s} 2}$ sıcaklık değerine yükseltilir. [19].

$$
\begin{gathered}
T_{s 1}=\frac{Q_{e s}}{m \cdot c_{p}}+T_{s o} \\
T_{s 2}=\frac{Q_{a \mathrm{t}}}{m \cdot c_{p}}+T_{s 1}
\end{gathered}
$$

\section{Dinamik Geri Ödeme Süresinin Hesaplanması}

Gaz motorlu birleşik ısı ve güç sisteminin karlılığı yatırım ve işletme maliyetlerinin az olmasına bağlıdır. Sistemin yatırımını değerlendirirken göz önüne alınabilecek bir kriter de yatırımın ne kadar sürede geri alınabileceği yani yatırımın kendini amorti süresidir. Sistemin geri ödeme süresinin kısa olması elde edilecek kazancın artmasını sağlayacaktır. Sistemin yatırım maliyeti ortaya çıktıktan sonra geri ödeme süresinin hesabında dinamik geri ödeme süresi yöntemi kullanılmıştır. Dinamik geri ödeme süresi hesaplanırken ilk yatırım maliyeti, yıllık net kazanç ve yıllık faiz oranı belirlenerek geri ödeme süresi hesaplanır. $\mathrm{G}_{\mathrm{i}}$ : yıllık net kazanç $(\mathrm{TL}), \mathrm{G}_{\mathrm{y}}$ : ilk yatırım maliyeti (TL), i: yıllık faiz oranı olmak üzere Geri ödeme süresi tg (yıl), eşitlik 3 ile bulunur.

$$
\operatorname{tg}=\frac{\ln \left\{\frac{G_{i}}{G_{i}-G_{y} . i}\right\}}{\ln (1+i)}
$$




\section{Bulgular Ve Tartışma}

4.1. Gaz Motorlu Birleşik Isı Güç Sisteminde Üretilen Enerji Miktarı ve Tüketilen Yakıt Miktarı Gaz motorlu birleşik ısı ve güç sisteminin yatırım maliyeti hesaplandıktan sonra doğalgaz kullanımı ile elde edilen işletme gelirleri ve işletme giderlerini belirleyecek sistem kapasitesi Çizelge 4.1'de verilmiştir. Bu kapasite değerlerine göre birim fiyatlar kullanılarak elde edilen işletme gelirleri her bir sistem için Çizelge 4.3'te görülmektedir.

Çizelge 4.1. Tcg v20 ile Tcg v16 gaz motoru kapasite tablosu

\begin{tabular}{|c|c|c|c|}
\hline \multicolumn{4}{|c|}{ TCG V16 } \\
\hline Modül Çalışma Saatleri & saat/y1l & 8.000 & 8.000 \\
\hline Yakıt Türü & & Doğalgaz & Doğalgaz \\
\hline Yakıt Isıl Değeri & $\mathrm{kcal} / \mathrm{m}^{3}$ & 8.250 & 8.250 \\
\hline Yakıt Tüketimi $(+\% 5$ tolerans $)$ & $\mathrm{kW}$ & 3.608 & 4.577 \\
\hline Yakıt Tüketimi & $\mathrm{m}^{3} / \mathrm{saat}$ & 376 & 477 \\
\hline Senelik Yakıt Tüketimi & $\mathrm{m}^{3} / \mathrm{y} 1 \mathrm{l}$ & 3.008.329 & 3.816.275 \\
\hline Elektrik Üretimi - Brüt $(\cos$ phi $=1)$ & $\mathrm{kWh}$ & 1.560 & 2.000 \\
\hline İç İhtiyaç ve Dahili Kayıplar & $\mathrm{kWh}$ & 30 & 38 \\
\hline Elektrik Üretimi - Net & $\mathrm{kWh}$ & 1.530 & 1.962 \\
\hline Senelik Elektrik Üretimi (Net) & $\mathrm{kWh} / \mathrm{y} 1 \mathrm{l}$ & 12.242.880 & 15.696.000 \\
\hline Yağ Tüketimi & $\mathrm{kg} / \mathrm{h}$ & 0,31 & 0,4 \\
\hline Egsoz 1s1 gücü ( $\pm \% 8$ tolerans) & $\mathrm{kWh}$ & 806 & 972 \\
\hline Ceket Isı Gücü ( $\pm \% 8$ tolerans) & $\mathrm{kWh}$ & 774 & 1005 \\
\hline $\begin{array}{l}\text { İntercooler } \quad( \pm \% 8 \text { tolerans }) \\
\end{array}$ & $\mathrm{kWh}$ & 134 & 178 \\
\hline Maksimum Toplam Isı Üretim Kapasitesi & $\mathrm{kWh}$ & 1.714 & 2.155 \\
\hline İșletme Toplam Isı Tüketimi $90 \%$ & $\mathrm{kWh}$ & 1.543 & 1.940 \\
\hline
\end{tabular}

Çizelge 4.2. Enerji güncel birim fiyatları tablosu

\begin{tabular}{|l|l|}
\hline En Birim Fiyatları Güncel & Ağustos-2021 \\
\hline Birim Elektrik Maliyeti & $0,6357 \mathrm{Tl} / \mathrm{kwh}$ \\
\hline Birim Doğalgaz Maliyeti & $1,27719 \mathrm{Tl} / \mathrm{kwh}$ \\
\hline
\end{tabular}

Çizelge 4.3. Tcg v16 sisteminin yıl boyunca üretilen enerji, tüketilen enerji ve maliyet dağılımı

\begin{tabular}{|c|c|c|c|c|c|c|c|}
\hline Aylık & $\begin{array}{l}\text { Elektrik } \\
\text { Tüketimi } \\
\text { kwh }\end{array}$ & $\begin{array}{c}\text { Üretilen } \\
\text { Elektrik } \\
\text { Enerjisi kwh }\end{array}$ & $\begin{array}{c}\text { Üretilen } \\
\text { Elektrik } \\
\text { Enerjisi Tl }\end{array}$ & $\begin{array}{l}\text { Üretilen Is1 } \\
\text { Enerjisi } \\
\text { kwh }\end{array}$ & $\begin{array}{l}\text { Üretilen Is1 } \\
\text { Enerjisi Tl }\end{array}$ & $\begin{array}{l}\text { Tüketilen } \\
\text { Yakıt } \mathrm{m}^{3}\end{array}$ & $\begin{array}{l}\text { Tüketilen } \\
\text { Yakıt Tl }\end{array}$ \\
\hline Ocak & 1676 & 1.241 .544 & $789.249,24$ & 1.719 & $137.524,82$ & 415,98 & $354.185,62$ \\
\hline Şubat & 1830 & 1.355 .623 & $861.769,75$ & 1.877 & $150.161,35$ & 454,20 & $386.730,12$ \\
\hline Mart & 2004 & 1.484 .519 & $943.708,52$ & 2.055 & $164.438,99$ & 497,39 & $423.501,18$ \\
\hline Nisan & 1913 & 1.417 .108 & $900.855,48$ & 1.962 & $156.971,95$ & 474,80 & $404.270,34$ \\
\hline Mayıs & 1855 & 1.374 .143 & $873.542,56$ & 1.903 & $152.212,74$ & 460,40 & $392.013,32$ \\
\hline Haziran & 1917 & 1.420 .071 & $902.739,13$ & 1.966 & $157.300,17$ & 475,79 & $405.115,65$ \\
\hline Temmuz & 2001 & 1.482 .296 & $942.295,78$ & 2.052 & $164.192,82$ & 496,64 & $422.867,20$ \\
\hline Ağustos & 1958 & 1.450 .443 & $922.046,54$ & 2.008 & $160.664,44$ & 485,97 & $413.780,10$ \\
\hline Eylül & 1876 & 1.389 .699 & $883.431,72$ & 1.924 & $153.935,90$ & 465,62 & $396.451,21$ \\
\hline Ekim & 1689 & 1.251 .174 & $795.371,10$ & 1.732 & $138.591,54$ & 419,20 & $356.932,88$ \\
\hline Kasım & 1913 & 1.417 .108 & $900.855,48$ & 1.962 & $156.971,95$ & 474,80 & $404.270,34$ \\
\hline Aralık & 1832 & 1.357 .105 & $862.711,58$ & 1.879 & $150.325,46$ & 454,70 & $387.152,78$ \\
\hline TOPLAM & 22464 & & $\mathbf{1 0 . 5 7 8 . 5 7 6 , 9 0}$ & & $1.843 .292,16$ & & 4.747.270,77 \\
\hline
\end{tabular}

30 | P a g e

www.iiste.org 


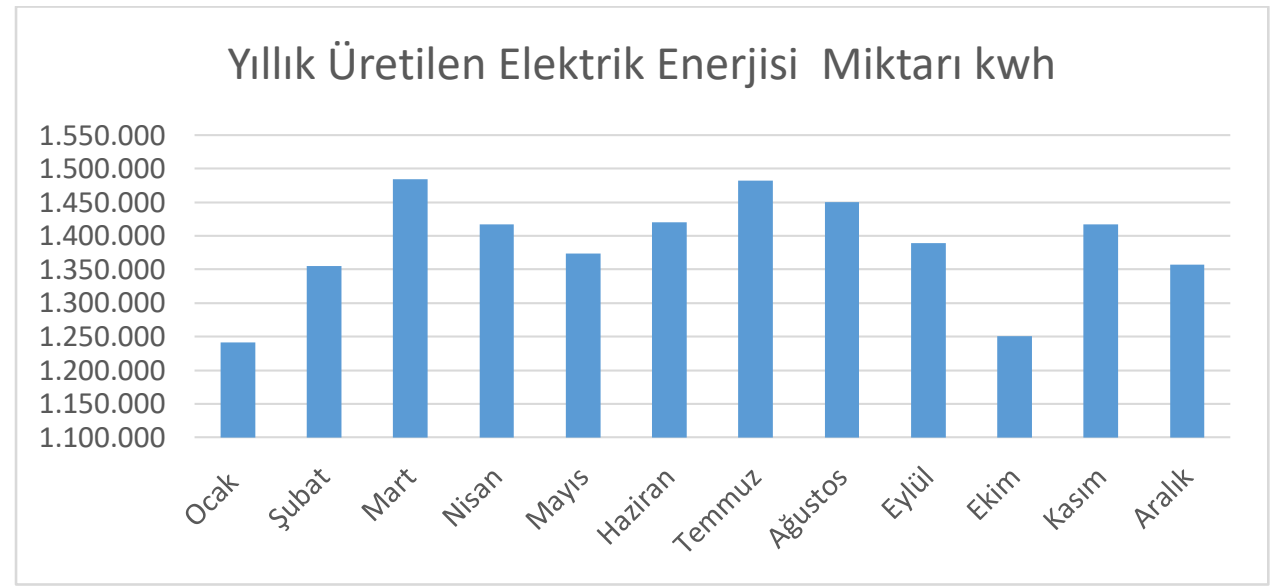

Şekil 4.1. Tcg v16 ısıl güç santrali ile yıl boyunca aylık üretilen elektrik enerjisi miktarları

$1.000 .000,00$

\section{Yıllık Üretilen Elektrik Enerjisi Değeri TL}

$950.000,00$

$900.000,00$

$850.000,00$

$800.000,00$

$750.000,00$

$700.000,00$

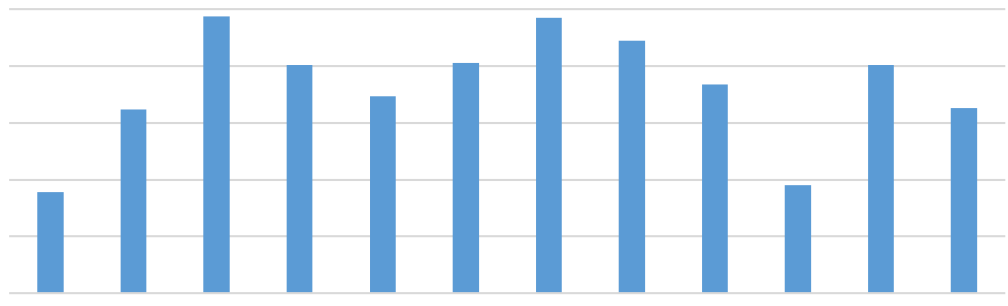

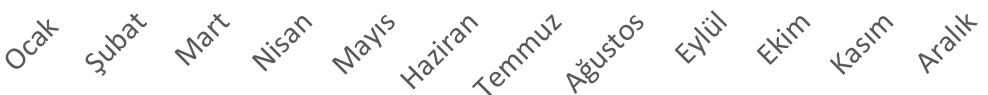

Şekil 4.2. Tcg v16 ssıl güç santrali ile yıl boyunca aylık üretilen elektrik enerjisi değerleri

Çizelge 4.4. Tcg v16/v20 model gaz motoru için yıllık kazanç değerleri tablosu

\begin{tabular}{|c|c|c|c|}
\hline \multirow{6}{*}{$\begin{array}{c}\text { İŞLETME GELİRLERİ } \\
\text { TL }\end{array}$} & \multirow{2}{*}{ ELEKTRIKK } & TCG V16 & 3.720 .429 \\
\hline & & TCG V20 & 4.769 .779 \\
\hline & \multirow{2}{*}{ ATIK ISI } & TCG V16 & 1.218 .701 \\
\hline & & TCG V20 & 1.532 .262 \\
\hline & \multirow{2}{*}{ TOPLAM } & TCG V16 & 4.939 .130 \\
\hline & & TCG V20 & 6.302 .042 \\
\hline \multirow{10}{*}{$\begin{array}{l}\text { İŞLETME GIDERLERİ } \\
\text { TL }\end{array}$} & \multirow{2}{*}{ DOĞALGAZ } & TCG V16 & 3.220 .429 \\
\hline & & TCG V20 & 4.085 .338 \\
\hline & \multirow{2}{*}{ YAĞLAMA YAĞI } & TCG V16 & 39.936 \\
\hline & & TCG V20 & 71.680 \\
\hline & \multirow{2}{*}{ BAKIM } & TCG V16 & 243.200 \\
\hline & & TCG V20 & 304.640 \\
\hline & \multirow{2}{*}{$\begin{array}{l}\text { TESIS SIGGORTA } \\
\text { BEDELI } \% 25 \\
\end{array}$} & TCG V16 & 9.728 \\
\hline & & TCG V20 & 11.168 \\
\hline & \multirow{2}{*}{ TOPLAM } & TCG V16 & 3.513 .293 \\
\hline & & TCG V20 & 4.472 .826 \\
\hline \multirow{2}{*}{$\begin{array}{l}\text { NET İŞLETME } \\
\text { KAZANCI (TL) }\end{array}$} & & TCG V16 & 1.425 .837 \\
\hline & & TCG V20 & 1.829 .216 \\
\hline
\end{tabular}

31 | P a g e

www.iiste.org 


\subsection{Gaz Motorlu Birleşik Isı Güç Sisteminin Ekonomik Analizi}

\subsubsection{Sistemin Ekonomik Analizi}

Sistem için ekonomik analiz, bir önceki bölümde tasarlanan sistem ile elde edilecek yakıt tasarrufu ve amortisman süresini hesaplayabilmek için yapılmaktadır. Ekonomik analiz yapılırken; ilk yatırım maliyetleri, ekonomik ömür, senelik bakım ve işletme harcamaları, senelik kar miktarı, hurda değeri ve faiz oranları önem arz etmektedir. Kurulacak sistem vasıtası ile geri kazanılan enerjinin yıllık maddi tasarruf miktarı Eşitlik 4 ile hesaplanmıştır. Eşitlikteki n, yatırımın faydalı ömrünü $A B$ yatırımın amortisman bedelini göstermektedir.

Çizelge 4.5 Birleşik ısı-güç çevrim santrali sisteminin yatırım maliyeti

\begin{tabular}{|l|l|l|}
\hline & \multicolumn{1}{|c|}{$\begin{array}{c}\text { TCGV16 Yatırım } \\
\text { Maliyeti TL }\end{array}$} & $\begin{array}{c}\text { TCG V20 Yatırım } \\
\text { Maliyeti TL }\end{array}$ \\
\hline Modül ve Yardımcı Ekipmanlar & $768.000,00$ & $896.000,00$ \\
\hline Isı geri kazanım sis. (Atık ısı kazanı) & $640.000,00$ & $768.000,00$ \\
\hline Step up Trafo ve OG Sistemi & $742.400,00$ & $742.400,00$ \\
\hline Motor soğutma ünitesi & $1.280 .000,00$ & $1.472 .000,00$ \\
\hline Nakliye, mekanik ve elektrik montajı & $268.800,00$ & $332.800,00$ \\
\hline İnşaat işleri (santrala ait bölümler) & $192.000,00$ & $256.000,00$ \\
\hline Toplam ilk yatırım maliyeti & $3.891 .200,00$ & $4.467 .200,00$ \\
\hline
\end{tabular}

Tcg v16 birleşik ısı sisteminin amortisman bedeli olarak sistemindeki sabit yatırım varlıklarının toplam maliyeti 3.891.200 $\mathrm{Tl}$ dir. Y1llık faiz oranı $\mathrm{i}=\%$ 5,5 ve sistem ömrü $\mathrm{n}=10$ yıl olarak kabul edilerek; AB amortisman bedeli, eşitlik 4 kullanılarak

$$
A B=I\left[\frac{i(1+i)^{n}}{(1+i)^{n}-1}\right] \quad \mathrm{TL} / \mathrm{y} 1 \mathrm{l}
$$

$$
\begin{aligned}
& \left.\mathrm{AB}=3.891 .200^{*}\left(0,055(1+0,055)^{\wedge} 10\right) /(1+0,055)^{\wedge} 10-1\right) \\
& \mathrm{AB}=516.362,24 \mathrm{Tl} / \mathrm{y} 1 \text { bulunur. }
\end{aligned}
$$

Tcg v20 Birleşik 1sı sisteminin amortisman bedeli olarak sistemindeki sabit yatırım varlıklarının toplam maliyeti 4.467.200 Tl dir. Yıllık faiz oranı $\mathrm{i}=\%$ 5,5 ve sistem ömrü $\mathrm{n}=10$ yıl olarak kabul edilerek; $\mathrm{AB}$ amortisman bedeli, eşitlik 4 kullanılarak,

$$
\begin{aligned}
& \left.\mathrm{AB}=4.467 .200 *\left(0,055(1+0,055)^{\wedge} 10\right) /(1+0,055)^{\wedge} 10-1\right) \\
& \mathrm{AB}=592.797,44 \mathrm{TL} / \mathrm{y} 1 \mathrm{l} \text { bulunur. }
\end{aligned}
$$

\subsection{Gaz Motorlu Birleşik Isı Güç Sisteminin Geri Ödeme Süresi}

Ekonomik analiz yapılırken sistemin dinamik geri ödeme süresi değerinden faydalanılmıştır. Bu değer ile dinamik geri ödeme süresi hesaplanarak kısa olan ödeme süresi sistemin daha karlı olduğunu gösterirken, uzun geri ödeme süresi sistemin karlılığının daha uzun dönemde ortaya çıkacağını göstermektedir. Daha kısa geri ödeme süresi veya daha uzun geri ödeme süresi için uygun bir faiz oranı ile daha uygun bir geri ödeme süresine ulaşılabilir.

\subsubsection{Sisteminin Dinamik Geri Ödeme Süresi}

Birleşik 1sı güç sisteminde dinamik geri ödeme süresi eşitlik 5 ile hesaplanır. Eşitlikteki n, yatırımın faydalı ömrünü AB yatırımın amortisman bedelini, i faiz oranını, Gi yatırımın yıllık net kazancını, Gy

32 | P a g e

www.iiste.org 
yatırım nakit maliyetini ifade etmektedir.

$$
\operatorname{tg}=\frac{\ln \left\{\frac{G_{i}}{G_{i}-G_{y} . i}\right\}}{\ln (1+i)}
$$

TCG V16 modeli için dinamik geri ödeme süresi,

Yıllık net kar Çizelge 4.4 'te toplam işletme karı olarak hesaplanan değer ile 1.425.837 TL dir. Tesisin ilk yatırım maliyeti ise Çizelge 4.5'daki verilere göre 3.891.200 TL' dir.

$\mathrm{G}_{\mathrm{i}}=1.425 .837 \mathrm{Tl}$

$\mathrm{G}_{\mathrm{y}}=3.891 .200 \mathrm{Tl}$

$\mathrm{i}=\% 5,5$

$$
\begin{aligned}
& \operatorname{tg}=\frac{\ln \left\{\frac{1425837}{1425837-3891200.0,05}\right\}}{\ln (1+0,05)} \\
& \operatorname{tg}=3,007 \mathrm{y} 1 \mathrm{l}
\end{aligned}
$$

bulunur.

TCG V20 modeli için dinamik geri ödeme süresi,

Yıllık net kar Çizelge 4.4 'te toplam işletme karı olarak hesaplanan değer ile 1.829.216 TL dir. Tesisin ilk yatırım maliyeti ise Çizelge 4.5'daki verilere göre 4.467.200 TL' dir.

$\mathrm{G}_{\mathrm{i}}=1.829 .216 \mathrm{Tl}$

$\mathrm{G}_{\mathrm{y}}=4.467 .200 \mathrm{Tl}$

$\mathrm{i}=\% 5,5$

$$
\operatorname{tg}=\frac{\ln \left\{\frac{1829216}{1829216-4467200.0,05}\right\}}{\ln (1+0,05)}
$$

$\operatorname{tg}=2,671 \mathrm{y} 1$

bulunur.

\section{Tartışma ve Sonuç}

$\mathrm{Bu}$ çalışmada, bir endüstri işletmesinde iki adet gaz motorlu birleşik isı güç sisteminin enerji ve ekonomik analiz çalışmaları ele alınarak, 1sı transferi analizi ve ekonomik değerlendirme için çeşitli hesaplar yapılmıştır. Sistemin kurulmasını işletmenin enerji ve buhar gereksinimlerine göre inceleyerek, iki tip gaz motoru ünitesinin enerji ve termoekonomik fizibilitesi yapılmış ve sistemin termoekonomik analizleri çıkarılmıştır. İşletme gereksinimlerine göre seçilen iki adet gaz motorundan Tcg v20 ile Tcg v16 arasında enerji ve ekonomik analiz sonuçları kıyaslanarak Tcg v20 gaz motorunun kullanılmasının işletme açısından daha efektif ve verimli olduğu ortaya konulmuştur. Yapılan çözümlemeler sonucu elde edilen değerlere göre; sisteme ait gaz motorlarının yakıt tüketimi yaklaşık 7.305.760 TL/yıl dir, atık ısıdan yıllık tasarruf miktarının 3.751.000 TL ve toplam yakıt tasarrufunun $2.206 .500 \mathrm{~m}^{3}$ olacağ 1 görülmüştür. 
Sonuç olarak enerji verimliliği esasına göre çalışan birleşik ısı ve güç sistemleri endüstriyel işletme için kârlı bir yatırımdır. Bu sistem işletme için sürekli elektrik enerjisi ve 1sı enerjisi sağlayacaktır. İşletmenin ihtiyaç fazlası elektrik enerjisi genel elektrik şebekesine satılarak daha fazla kazanç sağlamak mümkün olacaktır. Ancak sistemlerin ilk yatırım maliyetlerini daha kısa zamanda geri ödemeleri için birleşik elektrik-1Sı ve soğutma sistemi daha kârlı bir yatırım olacaktır. Ayrıca atık 1Sı kazanı uygulaması ile elde edilen buhar sayesinde 1 s1l verim artacak, beraberinde de atmosfere atılan NOx ve $\mathrm{CO}_{2}$ emisyonları azalacaktır. $\mathrm{NOx}$ ve $\mathrm{CO}_{2}$ emisyon oranı azalırken baca gazı kaynaklı çevre kirliliği de önlenecektir. Atık 1S1 geri kazanımın kullanıldığı benzer birleşik 1S1 ve güç sistemi uygulamalarında enerji ve yakıt tasarrufu yapılarak parasal kazanç değerinin artması benzer uygulamaların yatırıma dönüşmesini sağlayacak, işletmelerin enerji maliyetlerinin düşsmesi ile rekabetçi koşullarda başarılı olmalarının devamlı olması ile ülke ekonomisine yapacakları katkı artacaktır.

\section{Kaynaklar}

[1] Çiçek A., Ekmekçi, İ., Güven, H.R., "Bir Sanayi Tesisinde Kojenerasyon ve Atık Isı Geri Kazanımının İncelenmesi” SAU Fen Bilimleri Enstitüsü Dergisi, Cilt 7., Sayı 2., 2003.

[2] Dinçer İ., Al-Muslim H., "Thermodynamic analysis of reheat cycle steam power plants" International Journal of Energy Research., V.25., pp.727-739., 2001.(DOI:10.1002/er.717)

[3] Chang, S., Modeling Thermodynamic and Techno-Economic Analysis of Coke Production Process with Waste Heat Recovery, Energy, 141, 435-450 .,2017.

[4] Chen, Q., Finney, K., Li, H., Zhang, X., Zhou, J., Sharifi, V., Swithenbank, J., Condensing Boiler Applications in the Process Industry, Applied Energy, 89, 30- 36.,2012.

[5] Çengel A.Y. Boles AM. Thermodynamics: An Engineering Approach., Mc Graw-Hill, New York,2000.

[6] Yazıcı, H., Selbaş, R., "Bir buharlı güç santralinin enerji ve ekserji analizi” Selçuk Üniversitesi, Teknik Bilimler Meslek Yüksekokulu, Teknik Dergi., Cilt 10.,Sayı 1., 2011.

[7] Sürer F., "Kombine gaz/buhar türbinli kojenerasyon sistemlerinin termodinamik ve ekonomik analizi”, Yüksek Lisans Tezi, Yıldız Teknik Üniversitesi Fen Bilimleri Enstitüsü, İstanbul., 2003.

[8] Goel, N., Design and Performance Analyses of Condensing Heat Exchangers for Recovering Water and Waste Heat from Flue Gas, Lehigh University, Department of Mechanical Engineering, Master's Thesis, Ann Arbor, 1-107.,2012.

[9] Ünlü, C., Buharlı Sistemlerde Enerji Geri Kazanımı, Tesisat Mühendisliği, 108, 53-63.,2008.

[10] Rumeli, M., Simultaneous Industrial Waste Heat Recovery and Power Generation Using Heat Pipe Assisted Thermoelectric Generator, Manufacturing Engineering College of Science., RMIT University, Master's Thesis, Australia, 1-158., 2015.

[11] Çalışıcı Ü., Kojenerasyon Sistemleri ve Bir İşletmenin İhtiyacını Karşılayacak Kojenerasyon Sisteminin Teknik ve Ekonomik Uygulanabilirliği., Yüksek Lisans Tezi., Mustafa Kemal Üniversitesi Fen Bilimleri Enstitüsü., Antakya,2005.

[12] Sancar O., 2010. Ticari Binalarda Uygulanan Kojenerasyon ve Trijenerasyon Sistemlerinin Teknoekonomik Analizi. Yüksek Lisans Tezi. Yıldız Teknik Üniversitesi, Fen Bilimleri Enstitüsü. İstanbul.,2010. 
[13] Wang, D., Coal Power Plant Flue Gas Waste Heat and Water Recovery, Applied Energy Journal, 91, 341-348.,2012.

[14] Öztürk H., Kaya D., Kojenerasyon ve Trijenerasyon Tekniği Kitabı. Umuttepe Yayınları., 2014.

[15] He, B., Thermodynamic Analysis of a Low-Pressure Economizer Based Waste Heat Recovery System for a Coal-Fired Power Plant, Energy Journal, 65, pp. 80-90.,2014.

[16] Peris, B., Experimental Study of an ORC for Low-Grade Waste Heat Recovery in a Ceramic Industry, Energy Journal, 85, 534-542.,2015.

[17] Savruk N., Yeşin T., Gaz/Buhar Kombine Çevrim Enerji Santrallerinin Performans Analizi, Isı Bilimi ve Tekniği Dergisi., 2001.

[18] Paksoy A., K., Gaz motorlu bir 1sıl güç çevrim santralinin atık 1sı geri kazanımının termoekonomik analizi, Yüksek Lisans Tezi, K.S.Ü. Fen Bilimleri Enstitüsü., Kahramanmaraş, 2015.

[19] İmal M., Kaya A., Güneş M., Kuyumcu M. E., Sönmez K., Birleşik Isı ve Güç Üreten Sistemlerin Uygulamalı Analizi ve KSÜ Hastanesi Örnek Çalışması. KSÜ Mühendislik Bilimleri Dergisi, 18(2), 2015.

[20] Seyedkavoosi, S., Exergy-Based Optimization of an Organic Rankine Cycle for Waste Heat Recovery from an Internal Combustion Engine, Applied Thermal Engineering Journal, 126, 447-457., 2017.

[21] Yamankaradeniz, N., Tekstil Sanayiinde Atık Isıdan Yararlanılarak Enerji Tasarrufunda Klasik Sistem ile Isı Pompasının Karşılaştırılması, Uludağ Üniversitesi Müh. Mim. Fak. Dergisi, 12(1), 115-124.,2007. 